\title{
Os Fundamentos da Técnica da Transferência de 1895 a 1905
}

\author{
Fabiano Chagas Rabêlo \\ Universidade Federal do Ceará, CE, Brasil. \\ Carlos José Cerqueira Veras Filho \\ Universidade Federal do Piauí, PI, Brasil.
}

\author{
Leonardo Danziato \\ Universidade de Fortaleza, CE, Brasil. \\ Rodrigo Barbosa Silva Quadros \\ Universidade Federal do Ceará, CE, Brasil.
}

\author{
Gustavo Oliveira Carvalho \\ Universidade Federal do Piauí, PI, Brasil.
}

\begin{abstract}
Resumo: Este artigo é resultado de uma pesquisa bibliográfica, de caráter histórico e teórico, que investigou, de modo pormenorizado, a discussão em Freud sobre a transferência no período que vai de sua primeira descrição clínica até sua conceituação. Partimos do pressuposto de que para problematizar o manejo da transferência na clínica, o modo pelo qual este conceito foi construído é tão elucidativo quanto o seu conteúdo teórico, salientando que a transferência está no cerne do debate sobre a especificidade do método psicanalítico, seu estatuto de cientificidade e sua aplicação em diferentes contextos. Iniciamos com o comentário de sua descrição em 1895. É acompanhada a inserção de acréscimos metapsicológicos nos anos seguintes. Neles, o substantivo transferência vem designar ora o modo de funcionamento energético do psiquismo, ora a lógica causal da etiologia das neuroses. Esses acréscimos ensejam a reformulação da ideia de trauma e esclarecem o papel da fantasia e dos componentes sexuais na constituição dos sintomas. O livro dos sonhos consagra a transferência em uma acepção mais ampla, promovendo uma mudança da ideia de retroação, que recebe um sentido mais próximo ao de atualização. Freud retorna à transferência no sentido descritivo para problematizar a inclusão do analista nas formações do inconsciente do analisando. Depois de localizados os efeitos de duas crises - a dissolução do laço transferencial com Fliess e o impasse no tratamento de Dora - frisamos ao final como a conceituação da transferência acarreta uma mudança na abordagem do fenômeno da sugestão e da técnica da interpretação.
\end{abstract}

Palavras-chave: Transferência, Trauma, Fantasia, Sugestão, Interpretação. 


\title{
The Fundamentals of the Transference's Technique from 1895 until 1905
}

\begin{abstract}
This bibliographical research assembles the investigation of historical elements of psychoanalysis with the theoretical study of the transference from its first clinical description until its conceptualization. In reason to discuss the application of transference in the clinic, the investigation of the way in which the concept of transference was built is as instructive as the study of its theoretical content. This paper stresses that the transference is at the heart of the debate about the specificity of the psychoanalytic method, its scientific status and its application in different contexts. It begins with the review of its first description and follows the insertion of metapsychological grafts during the following years, in that the transference is used to designate the energy operating mode of the psyche and the causal logic of the etiology of neurosis as well. These additions impel a reformulation of the trauma idea and clarify the role of fantasy and sexual components in the formation of symptoms. The book of dreams establishes transference in a broader sense and transforms the meaning of the feedback's idea. Freud returns to the descriptive sense of transference to discuss the inclusion of the analyst in the formations of the unconscious of the one who is being analyzed. So, it highlights the effects of two crises: the dissolution of the transference bond with Fliess and the impasse in Dora's treatment. To conclude, it points how the first rudiments of the concept of transference provoke a change in the interpretation's technique and in the approach of the phenomenon of suggestion.
\end{abstract}

Keywords: Transference, Trauma, Fantasy, Sugestion, Interpretation.

\section{Los Fundamentos de la Técnica de Transferencia de 1895 hasta 1905}

Resumen: Se trata de uno trabajo bibliográfico que combina la investigación de elementos de la historia del psicoanálisis con el estudio teórico de la transferencia, desde su primera descripción clínica hasta su conceptualización. Se parte del supuesto de que, para problematizar su uso en la clínica, la forma en que fue construido el concepto de transferencia es tan instructiva como su contenido teórico. Se hace notar que la transferencia está en el centro del debate sobre la especificidad del método psicoanalítico, su condición científica y su aplicación en diferentes contextos. Se inicia con el rescate de su descripción en 1895. A continuación, el artículo sigue la adición de injertos metapsicológicos en los años siguientes. En ellos, la transferencia nomina tanto el modo de funcionamiento energético de la psique como la lógica causal de la etiología de las neurosis. Estas adiciones contribuyen para una revisión de la idea de trauma y aclaran el papel de la fantasía y de los componentes sexuales en la formación de los síntomas. El libro de los sueños establece la transferencia en un sentido más amplio. Freud entonces discute la inclusión del analista en las formaciones del inconsciente de quien está siendo analizado. Se señala el efecto de dos crisis: la disolución del vínculo de transferencia con Fliess y el callejón sin salida en el tratamiento de Dora. Al final, se afirma que los rudimentos de un primer concepto de transferencia implica un cambio en el enfoque del fenómeno de la sugestión y de la técnica de la interpretación.

Palabras clave: Transferencia, Trauma, Fantasia, Sugestion, Interpretación. 


\section{A Construção dos rudimentos do conceito de transferência}

A produção de uma resposta inédita para o fenômeno da transferência está na origem da psicanálise, em sua pré-história. É em torno da problematização desse fenômeno na clínica - por meio da hipnose, da sugestão e do método catártico - que Freud dá os primeiros passos no tratamento das chamadas "doenças nervosas”, dentre elas a histeria (Freud, 1915/1997). Apesar de já encontrarmos uma descrição do fenômeno em 1895, somente em 1905 a transferência é abordada como um conceito da técnica. Como consequência, vemos surgir então uma perspectiva mais precisa e refinada para uma série de problemas da clínica.

Este trabalho visa resgatar o percurso que vai da descrição do fenômeno da transferência à sua primeira conceituação, defendendo que a investigação do modo pelo qual o conceito de transferência se constitui na obra de Freud é tão importante para o entendimento de seu uso na clínica quanto o estudo do sumo teórico que desponta como resultado de seu percurso de elaboração. É objeto deste estudo os textos que apresentam, retomam, agrupam e articulam algumas concepções esparsas e fragmentadas sobre a transferência com o intuito de acompanhar o processo de construção do conceito e mapear os impactos de sua formulação. Com isso, encadeiam-se alguns apontamentos acerca da especificidade do método psicanalítico e sua aplicação.

Esta pesquisa se justifica em função de sua capacidade de instigar o questionamento sobre as diretrizes da clínica psicanalítica na atualidade. Quando nos é perguntado sobre o lugar que a psicanálise ocupa hoje na cultura e os diferentes contextos onde ela é aplicada, somos inevitavelmente remetidos ao conceito de transferência. Quando retornamos aos fundamentos da transferência, contextualizando as questões e situações que levaram à sua formalização, podemos concluir que ontem, assim como hoje, a clínica psicanalítica está em constante transformação. Daí a preocupação em situar um eixo de referência que torne possível reconhecer uma prática como psicanálise para, então, indagar suas potencialidades, limites e desdobramentos.

\section{Método}

Este artigo resultou de uma pesquisa bibliográfica, de cunho histórico e conceitual, que busca identificar na obra de Freud a lógica interna que leva à constituição do conceito de transferência, de modo microscópico, seguindo sua sequência cronológica passo a passo sempre quando possível. Foram escolhidos os textos do período que vai de 1895 a 1905, da descrição do fenômeno da transferência à sua primeira abordagem no âmbito da técnica. Esse recorte coincide com o período considerado por Mezan (2014) como sendo um primeiro sistema teórico de Freud, formado, como os três seguintes, pela articulação de uma teoria do psiquismo, uma teoria do desenvolvimento psicossexual, uma concepção psicopatológica das neuroses e uma leitura do processo terapêutico. Enfatizaremos em nossa discussão esse último aspecto.

Partimos do recenseamento das diferentes acepções que o termo transferência assume no texto freudiano para discriminar, primeiro, uma acepção mais coloquial, de onde deriva um amplo leque de significações (Maurano, 2006). Em seguida, é possível notar um uso clínico descritivo, de conotação mais específica. Por fim, localizamos a palavra transferência no contexto do vocabulário da metapsicologia. Temos então, com isso, uma rede de significações por meio da qual o uso cotidiano do termo contribui para a descrição do fenômeno que, por sua vez, antecede e prepara a conceituação. Uma vez estabelecido, essa primeira organização conceitual permite a retomada do fenômeno no âmbito da técnica sob uma nova perspectiva.

Além disso, é importante notar que esta conceituação não é construída de modo unívoco. A teorização da transferência ataca inicialmente diversos aspectos do fenômeno separadamente, valendo-se para isso da metapsicologia. Posteriormente, essas ilhas conceituais são coligidas numa única explicação. Segundo Miller (1987), o desenvolvimento do conceito de transferência ocorre pela articulação de três facetas (resistência, sugestão e repetição) e dois vieses (a transferência como motor e obstáculo para o tratamento). Buscaremos entender como essas facetas e vieses são coordenados em torno de um eixo teórico comum.

Este artigo é dividido em três partes. A primeira se ocupa dos textos freudianos que vão de 1895 a 1900. Em seguida, é discutido o período entre 1900 a 1905. Por fim, são comentados o caso Dora e o rompimento entre Freud e Fliess para especificar como esses eventos repercutem na conceituação da transferência.

Afora os textos freudianos do período citado no título, são realizadas referências a alguns artigos mais tardios nos quais Freud lança um olhar retrospectivo 
sobre o seu percurso de trabalho. Também são cotejadas as contribuições de comentadores de Freud. É da responsabilidade dos autores a tradução de termos freudianos quando seguidos da palavra em alemão entre parênteses.

\section{De 1895 a 1900 - dos Estudos Sobre Histeria ao livro dos sonhos}

Como assinalado por vários autores (Maurano, 2006; 2010; Mezan, 2014; Porge, 2003; Rabêlo, \& Dias, 2013), é possível encontrar nos Estudos Sobre Histeria (Breuer, \& Freud, 1895/1999) uma primeira descrição clínica do fenômeno da transferência. Freud a define como uma tendência por parte do paciente em constituir uma falsa aliança ou conexão com o médico. Ela é concebida como um fenômeno pontual e contingente, restrito às expressões patológicas da histeria. Seu caráter de obstáculo é enfatizado em detrimento de sua função de motor do tratamento, que permanece velada (Maurano, 2006; Porge, 2003). Por isso, Freud destaca a influência da interpretação, da cooperação do analisando e da autoridade do analista no trabalho que leva à superação das resistências (Breuer, \& Freud, 1895/1999).

Apesar dessa descrição precoce, não é possível nesse momento extrair dela as consequências clínicas mais significativas que marcam a discussão sobre a transferência na obra freudiana, principalmente se for levado em consideração o ciclo de artigos técnicos na primeira metade da década de 1910. Falta-lhe principalmente os referenciais metapsicológicos para que o fenômeno da transferência possa ser interrogado a partir da perspectiva da dinâmica psíquica (Honda, 2013; Mezan, 2014). Doravante, o desafio de Freud está em, com o auxílio da metapsicologia, descobrir a lógica inerente à dinâmica que enlaça transferência, resistência e sexualidade.

O primeiro passo nesse sentido é o abandono da teoria da sedução em prol da ideia de fantasia (ou realidade psíquica). Essa mudança, por sua vez, ocorre em etapas, de forma simultânea e solidária à transformação na concepção de trauma. Ao final dessa etapa, temos que, de uma realidade factual, circunscrita a um evento datado, o trauma passa a ser descrito como uma condição estrutural do psiquismo (Andrés, 2013; Castilho, 2013), que Freud situa no cerne da fantasia. A ideia de fantasia vem substituir a função que o trauma ocupava inicialmente na etiologia da histeria.
Em diversos aspectos, essa nova abordagem do trauma repercute na elaboração do fenômeno da transferência. Todavia, há vários pequenos elos da elaboração metapsicológica que preparam essa mudança. Uma conexão importante já apresentada por Freud (Breuer, \& Freud, 1895/1999) nos Estudos Sobre Histeria é o recalque (Verdrängung), que desponta como ação psíquica reguladora do trauma e como o principal mecanismo da etiologia das neuroses. Uma outra referência importante pode ser encontrada na carta endereçada a Fliess de $1^{\circ}$ de janeiro de 1896 (Carta 39), onde o sintagma "processos de transferência" (Übertragungsvorgänge) (Freud, 1887-1902/1962, p. 127, 162) é utilizado para designar o fluxo livre de energia no sistema psi $(\Psi)$, que constitui a característica principal do processo primário, próprio do sistema inconsciente. Essa energia livre, de acordo com essa perspectiva, tende a seguir os caminhos já previamente facilitados no sistema psi $(\Psi)$. Esse uso do termo transferência repete-se no Projeto para a Psicologia Científica (Freud, 1887-1902/1962).

Outro acréscimo metapsicológico relevante está na carta 52. Nela, Freud (Freud, 1887-1902/1962; Masson, 1986) expõe o que Dunker (2013) denomina "modelo da multiextratificação linguística" (p. 75). Trata-se de uma concepção de aparelho psíquico, no qual a memória é produzida e atualizada ininterruptamente pela interação de diferentes estamentos ou níveis de registros, cada um deles com uma sintaxe própria. A passagem de conteúdo de um nível para o outro pressupõe um complexo processo que envolve não apenas a inscrição de novos traços perceptivos, mas também transcrições e traduções de conteúdos preexistentes. Por isso, a referência à carta 52 permite a Ayouch (2015) descrever a transferência como o processo de tradução e atualização psíquica do trauma na relação com o analista.

Esses dois desenvolvimentos teóricos (a concepção energética do Projeto e o modelo de memória da carta 52) são pré-requisitos para uma reformulação da explicação do trauma e, consequentemente, da etiologia da neurose. Assim, um ano antes da carta onde Freud diz não acreditar mais em sua neurótica (sua teoria da sedução), no artigo Sobre a Etiologia da Histeria, ocorre um uso bastante específico e significativo do termo transferência. Freud (1896/1997) utiliza diversas vezes o verbo "transferir" e o substantivo "transferência" (Übertragen, Übertragung) (p. 69, 70, 76, 77) no seu modelo explicativo da gênese 
das psiconeuroses. Ao retirar a ênfase da sedução, propõe como alternativa a ideia de uma complexa rede de representações através das quais as intensidades psíquicas se deslocam. Para ele, essa rede tem por função metabolizar as quantidades energéticas que desencadeiam o adoecimento psíquico. Com isso, o aparelho psíquico adquire o poder de potencializar ou enfraquecer o peso da influência do evento traumático. Embora nesse momento ainda persista como principal elemento do esquema que explica a origem da histeria, o peso do trauma na causação das neuroses passa nitidamente por uma revisão. $\mathrm{O}$ trauma é concebido a partir de então menos como o impacto direto de um evento momentâneo e mais como uma insuficiência na elaboração das quantidades de energia.

A partir desse ponto, o termo transferência passa a ser associado à tese da etiologia sexual das neuroses, o que culmina na construção da proposta de equação (ou sequência) etiológica, que é enriquecida nas décadas seguintes, principalmente a partir dos Três Ensaios Sobre a Sexualidade. Trata-se de uma fórmula por meio da qual os elementos envolvidos na produção do adoecimento são articulados. Essa fórmula explica a "ação retroativa" (nachträgliche Wirkung) (Freud, 1898/1997, p. 31) do efeito traumático pelo deslocamento de intensidades de um evento do passado para um acontecimento atual, mobilizando nesse processo a constituição psíquica de cada pessoa.

André (2013) chama atenção para o caráter temporal duplo que a ideia de retroação possui nesse modelo etiológico. O autor faz notar dois instantes do trauma que participam simultaneamente de sua definição: de um lado, a ação psíquica desorganizadora, suposta no passado; de outro, sua significação posterior, que acusa a existência do golpe e o evidencia. Dessa discussão, é pertinente destacar que inicialmente, em função de sua contaminação pela teoria da sedução, a ideia de retroação na etiologia freudiana possui um sentido que pode ser chamado de arqueológico e conservador, na medida em que sua ênfase recai na influência das reminiscências de um evento do passado, cujas cargas afetivas precisam ser descarregadas e metabolizadas.

É importante lembrar que o paralelo entre o tratamento analítico e o trabalho de escavação de ruínas na arqueologia já está presente em Freud desde os Estudos sobre Histeria (Breuer, \& Freud, 1895/1999), repetindo-se em diversos momentos posteriores de sua obra. No entanto, nos textos mais tardios, em especial
Construções em Análise (Freud, 1937/1997), o sentido dessa metáfora se transforma sensivelmente. Nesse texto, o ponto de destaque da arqueologia psíquica recai mais no esforço de abstração que cabe ao analista realizar para situar as coordenadas do sujeito na fantasia do que na esperança de acessar diretamente o material mnêmico de um evento da infância que se encontra escotomizado.

É possível afirmar que na carta a Fliess de 2 de maio de 1897, (Freud, 1887-1902/1962; Masson, 1986) já se encontra pavimentado o caminho para o abandono definitivo da teoria da sedução. Freud escreve que o elemento recalcado não é uma lembrança, mas impulsos que se mobilizam em torno de cenas imaginárias. Nos rascunhos $\mathrm{M} \mathrm{e} \mathrm{N}$, ainda nas cartas a Fliess, reconhece o caráter ficcional e compósito da cena traumática, que se vale de elementos heterogêneos e independentes para sua montagem (Vidal, 2010).

Também no rascunho $\mathrm{N}$ há a menção à palavra transferência em um sentido que faz fronteira entre o uso coloquial e o clínico-descritivo. Aqui a transferência designa um processo de atualização da estrutura da fantasia, que Freud concebe como análogo ao mito de Édipo na tragédia de Sófocles. Após reconhecer a manifestação de impulsos sexuais da criança direcionados aos pais, Freud afirma que é possível constatar nas criadas que prestam serviços domésticos uma situação similar. Nesse caso, os patrões vêm substituir os pais como alvo dos investimentos sexuais. Escreve que não é raro nessas situações a presença da fantasia - atravessada muitas vezes por sentimentos de culpa e autorecriminações - de que em algum momento a patroa morrerá, deixando o caminho livre para a concretização de um romance com o patrão, alimentado em segredo. Trata-se de um pequeno clichê, apresentado como uma espécie de vinheta clínica, que se assemelha ao caso de Lucy, publicado nos Estudos sobre Histeria (Breuer, \& Freud, 1895/1999). De toda forma, é possível reconhecer nesse curto comentário uma antecipação de alguns aspectos da transferência que posteriormente o conceito irá fixar.

No texto A Sexualidade na Etiologia das Neuroses (1898/1997), verifica-se uma importante articulação teórica. Ao final desse texto, Freud aproxima o trabalho de mediação psíquica na etiologia das psiconeuroses com o processo de formação dos sonhos. Nesse ponto, faz referência A Interpretação dos Sonhos, ainda no prelo, onde promete apresentar os "fundamentos de uma psicologia das neuroses" (1898/1997, p. 32). 
O paralelo entre o sintoma e outras formações psíquicas não patológicas é explorado em dois pequenos artigos do final do século. XIX. Neles, ao se dedicar à investigação das lembranças encobridoras, Freud tem também a oportunidade de avançar na construção de um modelo explicativo do processo de constituição dos sintomas neuróticos. Esse modelo será posteriormente transposto para a explicação da transferência por meio da constatação de que, pela transferência, o analista torna-se parte integrante das formações do inconsciente do analisando.

No texto em que Freud (1898/1999) discute os lapsos de memória, há valiosos apontamentos sobre os objetivos da psicanálise a partir da consideração ao sintoma como formação de compromisso. Dada a sua importância, uma frase deste texto foi escolhida para uma análise mais detalhada. Freud escreve que o tratamento psicanalítico deve proporcionar a "correção" (Redressement, em francês no original) dos recalques e deslocamentos. Para que isso ocorra, faz-se necessário a "reconstrução" (Wiedereinsetzung) do "verdadeiro" (eigentlichen) objeto psíquico (p. 525) posto em causa pelo sintoma.

Trazendo a discussão para o campo da fantasia, pode-se afirmar que esse objeto em função do qual o sintoma é produzido como resposta não é um elemento apreensível imediatamente pela percepção, mas algo que é visado pelas manobras por meio das quais o analisando obtém a realização de suas tendências desejantes. Logo, o analista, ao consentir com os investimentos libidinais do analisando, ocupa uma posição que lhe permite reconstruir esse objeto a partir das coordenadas da cena da fantasia que é atualizada na transferência. Essa reconstrução, por sua vez, possibilita o redirecionamento do jogo de forças que sustenta e perpetua o sintoma. Vale a pena destacar o termo eigentlich (em alemão: real, verdadeiro) que aponta para a qualidade peculiar desse objeto conjurado pelo tratamento analítico. Freud retorna a essa questão no texto Sobre o Amor de Transferência, de 1914, quando se interroga acerca do caráter factual do amor no fenômeno da transferência (Freud, 1915/1997).

No ano seguinte, Freud (1899/1999) utiliza o mesmo modelo explicativo das formações de compromisso para descrever o processo de constituição das lembranças encobridoras. Com o auxílio de referências tomadas de empréstimo da física mecânica, define as formações de compromisso como a "resultante" mediana que surge da interação de duas ou mais forças que atuam no mesmo ponto. Daí a menção ao modelo do "paralelograma de forças" (Resultirenden im Kräfteparallelogramm) (p. 536) para demonstrar a produção de novos vetores e direções a partir da interação das tendências em conflito.

\section{De 1900 a 1905: da Interpretação dos Sonhos ao Caso Dora}

A partir de 1900, a transferência é associada ao mecanismo de deslocamento no trabalho de formação dos sonhos (Freud, 1900/1997). Ocorre aqui a retomada da noção de transferência expressa na carta 39 e no Projeto para uma Psicologia Científica, só que dessa vez a ênfase não está nos aspectos energéticos e econômicos, mas nos elementos formais e linguageiros, cuja sintaxe pode ser reconstruída e verificada por meio da técnica da interpretação. A ideia de retroação também recebe uma nova inflexão. Ela passa a ser utilizada no sentido de uma atualização das possibilidades de significação de uma rede de traços de memória.

É possível notar, nos textos desse período, a variação na grafia da palavra transferência, escrita ora no singular, ora no plural (Baratto, 2010; Porge, 2003), observação, aliás, que remonta a Laplanche e Pontalis (1998), no Vocabulário de Psicanálise. O que parece ser relevante dessa discussão é que tal variação pode ser tomada como índice de um movimento de ampliação e convergência na elaboração do fenômeno da transferência. Isto é, a construção de um aparato teórico mais preciso possibilita contemplar numa única explicação uma série de descrições e considerações até então tratadas isoladamente. Paulatinamente, as transferências são subsumidas em um único modelo explicativo, que recebe a denominação de transferência, no singular.

Essa ampliação do alcance da transferência prepara uma reviravolta na técnica. Baratto (2010) propõe uma comparação, que muito provavelmente não deve ter passada desapercebida à Freud. Ela sugere que o analista ocupa no tratamento uma função análoga a dos restos diurnos no trabalho de formação dos sonhos. Os restos diurnos (Freud, 1900/1997) são traços mnêmicos recentes, pré-conscientes, de baixa valência psíquica que, por possuírem uma associação indireta com uma representação inconsciente recalcada, permitem a constituição de vias alternativas para o escoamento de energia.

É possível encontrar novamente, na carta de 16 de abril de 1900 endereçada a Fliess, a referência à 
transferência no sentido clínico descritivo (Freud, 1887-1902/1962; Masson, 1986), mas com uma novidade. Nesse momento, Freud já percebe que o analista está concernido no sintoma do analisando. Referindo-se ao caso de um paciente ao qual planeja dar alta, Freud se interroga a respeito do caráter assintótico do processo de cura analítico e constata como um problema a manutenção de um resíduo sintomático - o vínculo transferencial com o analista - após o encerramento do tratamento. Segue a transcrição de um trecho dessa carta a partir da versão apresentada por Masson, que é a mais extensa e completa:

Estou começando a entender que a aparente interminabilidade do tratamento é algo que ocorre regularmente e está relacionado à transferência. Espero que esse remanescente não desmereça o sucesso prático. Eu poderia ter continuado o tratamento, mas tive a sensação de que tal prolongamento seria um compromisso entre doença e saúde, que os próprios pacientes desejam e que o médico não deve concordar com ele (Masson, 1986, p. 410).

Em Psicopatologia da Vida Cotidiana (Freud, 1901/1999), Freud aplica o termo transferência ao processo de constituição de outras formações de compromisso além dos sonhos e os sintomas, tais como os lapsos, os esquecimentos e as superstições. Logo depois, no livro dos chistes (Freud, 1905/1997c), há uma passagem bastante interessante de onde é possível inferir uma inflexão no modo de participação do analista nas formações de compromisso do analisando. Esse trecho será comentado mais detalhadamente.

Ao propor a existência de um cálculo na economia psíquica da produção do riso que inclui o outro como um lugar de endereçamento, como uma espécie de catalisador do jogo de forças da dinâmica psíquica, cria-se a possibilidade de pensar o lugar do analista na transferência como uma situação análoga. Tal perspectiva não está desenvolvida, mas, dada a sincronia da escrita entre o posfácio do caso Dora e o livro dos chistes (que logo explicitaremos), essa conexão implícita demonstra ser bastante profícua.

Essa linha de pensamento, se levada até as últimas consequências, incita uma atitude de reserva e cautela no que tange à consideração da efetividade de uma proposta de autoanálise. Tal argumento corrobora a atitude tomada por Freud a partir de então de tratar com mais cuidado o problema da formação do analista. Há aí uma questão controversa: o percurso freudiano que levou à invenção do inconsciente não pode ser tomado como modelo para a formação dos analistas que vieram depois dele. Doravante, a transferência se tornará um ponto crucial na discussão sobre a transmissão da psicanálise. Nesse momento, contudo, o tema da formação do analista não recebe destaque em função do isolamento na comunidade científica que Freud experimenta em decorrência do ineditismo de sua descoberta (Freud, 1914/1999; Gay, 1989). Essa discussão ganhará gradualmente mais visibilidade e interesse à medida que o movimento psicanalítico se amplia.

Nos anos que precedem a publicação do caso Dora, Freud lança dois artigos sobre técnica que chamam atenção pela ausência do termo transferência no sentido metapsicológico e descritivo (Freud, 1904/1997; 1905/1997a), a saber: O Método Psicanalítico Freudiano e Sobre Psicoterapia. Apesar disso, há nesses textos uma lacuna teórica bem delineada onde a discussão sobre a transferência vai se instalar.

A respeito do primeiro desses textos (Freud, 1904/1997), há um uso bem peculiar e coloquial do verbo transferir. Num retrospecto das diversas técnicas que utilizou, Freud, ao destacar o diferencial do método catártico, aponta que nele "a eficácia (Wirksamkeit) terapêutica não é transferida (übertragen) para uma sugestão de proibição (suggestiven Verbot) exercida pelo médico" (p. 102).

É lícito depreender dessa passagem que o projeto terapêutico freudiano inclui uma filtragem da excessiva interveniência da autoridade do médico, substituindo-a, quando possível, por uma intervenção nos processos psicodinâmicos atuantes na produção do sintoma.

Nesse contexto, Freud lembra que um dos pré-requisitos para aplicação do método catártico é que o paciente seja hipnotizável. Com isso, reconhece no método de Breuer um modo de sugestão não proibitivo que é mediado pela hipnose, cuja função é mobilizar algumas tendências psíquicas que atuam no sentido de desestabilizar o equilíbrio de forças garantido pelo sintoma. Surge daí o desafio de esclarecer como essas tendências podem ser conjuradas na ausência da hipnose. A associação livre esclarece esse problema apenas parcialmente na medida que favorece o surgimento de substitutos do recalcado e força a reprodução das resistências vigentes. Freud, no entanto, reconhece que a reprodução do recalcado mobiliza não só "pensamentos" (Gedanken), mas tam- 
bém "moções pulsionais" (Regungen) (p. 103). Com isso, é lícito formular a pergunta se, nesse momento, a participação da economia psíquica na equação que explica o processo analítico ainda não estaria suficientemente elucidada.

O texto Sobre Psicoterapia (Freud, 1905/1997b) inicia-se com a pergunta: como "o tratamento (psicanalítico) opera e sobre quais bases ele se fundamenta" (p. 117). Para responder a essa questão, Freud lembra o argumento de que a personalidade do médico é o seu principal instrumento de trabalho no contexto de todo tratamento psíquico. Em seguida, faz remontar a eficácia do tratamento analítico a uma tendência - literalmente, uma compulsão psíquica (psychische Zwang) - oriunda do inconsciente que insiste em se manifestar. A partir da referência ao modelo de divisão psíquica da primeira tópica, assinala que a emergência de conteúdos inconscientes acirra forças de resistência, o que leva a produção de desprazer. Defende então que tal fato requer que o analista exerça "uma parcela de trabalho educativo" (p. 118) com o intuito de evitar a regulação automática de desprazer - o recalque - que acompanha as atualizações das tendências inconscientes. Trata-se de uma "pós-educação a serviço da superação das resistências", afirma (p. 118). Destaca em seguida que tais resistências atingem principalmente os conteúdos da vida sexual e amorosa.

A (pós-)educação mencionada apoia-se, portanto, no uso da autoridade do médico para superar as resistências do analisando. Apesar desse comentário, Freud descreve o procedimento do tratamento psicanalítico como radicalmente disjunto do modo como as psicoterapias fundamentadas na sugestão funcionam. Para ele, a análise opera pela retirada de elementos da constituição psíquica, enquanto as psicoterapias sugestivas intervém por acréscimo.

Embora correta, essa explicação logo vai se mostrar insuficiente, pois elide o fato de que há inevitavelmente um componente sugestivo no vínculo analítico. Como tributária da alienação constitutiva do sujeito a uma alteridade, a sugestão está presente em qualquer modalidade de laço social, inclusive na psicanálise. A diferença entre a psicanálise e outras práticas terapêuticas não pode, portanto, ser situada na ausência ou presença da sugestão, mas no uso que se faz dela (Porge, 2013). A problematização do fenômeno da transferência possibilitará que essa questão seja retomada e desenvolvida com mais precisão.
Trata-se de um tema relevante e atual, pois Freud situa no embricamento entre fenômenos transferenciais e sugestivos uma significativa parcela das dificuldades da prática psicanalítica em contextos institucionais (Freud, 1915/1997; 1919/1997). Além disso, essa dificuldade de operar com as relações de conjunção e disjunção entre transferência e sugestão na clínica toca diretamente no debate sobre a especificidade metodológica da psicanálise. Mezan (2014) desenvolve uma interessante discussão a esse respeito a partir do comentário dos argumentos de Grünbaum. De acordo com Mezan, Grünbaum defende que há uma inconsistência fundamental e incontornável do método clínico psicanalítico em função da contaminação dos seus resultados pelo fenômeno da sugestão. Mezan, a seu turno, apresenta uma outra via de resolução do problema. Para ele, é fundamental distinguir os efeitos analíticos dos propiciados pela sugestão em estado bruto. Trata-se, para o autor, de um problema de base da investigação psicanalítica.

O estabelecimento do conceito de transferência, portanto, constitui uma via de isolar, distinguir e filtrar os efeitos da sugestão na clínica psicanalítica, além de esclarecer os meios que faz o trabalho da análise avançar. Daí que a referência à transferência na obra de Freud é acompanhada pela necessidade de adoção de uma atitude de abstinência por parte do analista (Freud, 1915/1997) no que tange ao exercício de sua autoridade e ao uso da sugestão. Muito embora o termo neutralidade esteja incluso no vocabulário e no projeto clínico freudiano, é lícito propor que a problematização do fenômeno da transferência torna manifesta a impossibilidade da manutenção na clínica psicanalítica de um ideal de neutralidade científica, pelo menos tal como está presente nas ciências naturais.

Ainda no texto Sobre Psicoterapia, Freud (1905/1997b) chama atenção para um outro problema ainda não solucionado, que persiste ao lado da dificuldade na explicação econômica do processo analítico e da mediação dos efeitos da sugestão. Para ele, a condução do tratamento psicanalítico não se reduz a um processo mecânico, o qual alguém pouco familiarizado poderia facilmente assimilar. Defende que o psiquismo humano possui muitos meandros e sutilizas que demandam um preparo específico e um cuidado especial por parte daquele que aceita o desafio de escutar pacientes em psicoterapia. Então, cita uma passagem da peça de Shakespeare, quando Hamlet ironiza dois de seus súditos que receberam a incum- 
bência de descobrir a causa de sua infelicidade para então trazer-lhe de volta a alegria. Hamlet pede a um deles que pegue uma flauta e toque. Diante da falta de habilidade do súdito no trato com o instrumento musical, o príncipe da Dinamarca compara a alma humana à flauta. Para ele, tanto a alma como a flauta requerem habilidade e experiência de quem os manuseia para que uma boa música possa ser produzida.

Freud assinala com essa metáfora que há um elemento suplementar na técnica psicanalítica que ainda não está suficientemente esclarecido e que o manejo da situação analítica não se esgota no debate sobre a interpretação (Costa e Silva, 2014). Até aqui, a ênfase da explicação do processo de cura recai na interpretação e na influência educativa da autoridade do médico. Há nessas duas diretrizes os fundamentos do que Mezan (2014) considera a noção implícita de transferência, que vigora em Freud até 1905. Tal situação mudará drasticamente com a formalização do primeiro movimento de conceituação da transferência no âmbito da técnica.

\section{O Caso Dora e o rompimento com Fliess}

Para que uma definição unificada da transferência seja consolidada, faz-se necessário a conjugação dos efeitos de duas crises: de um lado, a localização e a elaboração de uma insuficiência na clínica; de outro, a dissolução do vínculo de trabalho com Fliess. Cada uma desses acontecimentos, a seu modo, enreda Freud na pesquisa sobre o lugar que o analista ocupa nas manifestações da transferência.

Há, no encadeamento desses episódios, duas características bastante significativas do processo de elaboração do conceito de transferência: a precedência do fazer clínico em relação ao conceito e a indissociabilidade entre transferência e contratransferência. Daí que o exercício de construção do caso torna-se a via privilegiada pela qual o analista busca dar conta das consequências de seu ato na temporalidade própria que é exigida pela consideração ao inconsciente. A partir das contribuições de Bursztyn e Figueiredo (2012), é instrutivo constatar como Freud se coloca no lugar de aprendiz da clínica (p. 143), esforçando-se ao máximo em submeter os conceitos à singularidade das manifestações subjetivas de cada paciente. Como consequência, nos casos e fragmentos clínicos publicados por Freud a formulação de um problema ainda sem solução é tão ou mais importante quanto a resposta que ele oferece. Há o traço de um pathos - de uma manifestação afetiva singular e paradoxal - que esses textos buscam apreender e que serve de bússola para a produção teórica futura. Daí a importância do caso Dora: trata-se de um malogro que permite a Freud ressignificar retroativamente o acumulado clínico de uma série de casos com os quais se ocupou.

Na introdução, Freud (1905/1997) afirma que o seu objetivo inicial de ao escrevê-lo foi o de demonstrar a aplicação da técnica da interpretação dos sonhos no contexto de um caso clínico. Em função disso, o livro é organizado em torno da interpretação de dois sonhos a partir dos quais a lógica do tratamento é deslindada. Essa proposta, contudo, é subvertida pela consideração ao fenômeno da transferência, que desponta como chave para o entendimento do impasse que leva à interrupção prematura do tratamento. Desse modo, Freud apresenta o testemunho de uma insuficiência, cujo reconhecimento permite pela primeira vez que o tema da transferência seja tratado como uma questão da técnica.

Seguindo as indicações do prefácio do livro, Freud apresenta a seguinte sequência cronológica: em 1900, antes do ano novo, Dora abandona o tratamento que havia se iniciado três meses antes. Pouco tempo depois, redige grande parte do texto, que publica apenas em 1905. Dora volta a procurar Freud novamente em 1902, pouco mais de um ano depois do último encontro, quando lê em um jornal a notícia da sua nomeação para o cargo de Privatdozent. Na ocasião, ela se compromete a retomar os atendimentos. Freud escuta e acolhe essa promessa, no entanto o faz com ceticismo. De fato, conforme suspeitava, ela não o procura novamente.

O relato desse último episódio é incorporado ao texto numa descrição lacônica. Suas lacunas, no entanto, levam o leitor a se interrogar sobre algo que, ao mesmo tempo em que é assinalado, escapa à apreciação de Freud nesse primeiro tempo. Isso que permanece intocado durante tratamento é retomado como tema central do posfácio, que constitui uma espécie de programa teórico onde Freud antecipa em linhas gerais o que será desenvolvido nos anos seguintes sobre a transferência. Com isso, Freud reconhece a contribuição de um forte componente contratransferencial que limitou o progresso do tratamento.

Há então o intervalo de três anos entre o último encontro de Freud com Dora e a publicação do caso clínico; quatro, se a referência for a data do término do tratamento. Concordamos com Mezan (2014) 
e Gay (1989) ao afirmar que esse adiamento ocorreu principalmente em função do tempo de elaboração exigido para formulação de uma nova abordagem do fenômeno da transferência. A respeito do posfácio, sua independência em relação à estrutura do livro (cujo foco é a interpretação), sua brevidade e o fato de conter uma abordagem inédita do problema da transferência corroboram a hipótese de que ele deve ter sido concluído muito próximo da publicação do livro, em 1905. Faz-se necessário, contudo, ponderar que Freud justifica o adiamento da publicação em função de uma preocupação com o sigilo e a manutenção do anonimato da paciente. Tal fato, no entanto, não invalida os argumentos dos autores acima referidos.

Essa contextualização torna possível diferenciar no caso Dora dois momentos distintos de apreciação do fenômeno da transferência. O primeiro deles encontra-se no segundo capítulo, onde Freud destaca uma associação de ideias de sua paciente que denota o investimento sexual na sua pessoa. Freud é tomado por Dora como substituto de seu pai a partir de um traço comum a ambos: o fato de serem fumantes. Referindo-se nominalmente à transferência no sentido clínico descritivo, descreve esse investimento como carregado por um forte afeto de asco e repulsa. Nesse momento, talvez pela primeira vez, Dora explicita sua intenção de interromper o tratamento

Destaca-se nesse momento a ênfase dada por Freud ao caráter inflamável da transferência, o que pode ser verificado a partir das associações de Dora que vinculam conteúdos sexuais ao elemento fogo (Freud, 1905/1997c). No ciclo de artigos sobre a técnica, Freud (1915/1997) é mais explícito acerca desse aspecto explosivo da transferência, traçando uma comparação do químico que maneja substâncias instáveis e o ofício do analista. Talvez essa metáfora encontre no contexto da análise do primeiro sonho de Dora a sua referência matriz (Maurano, 2010). De qualquer forma, a dificuldade no manejo das tensões sexuais no tratamento de Dora constitui um forte indicativo de um problema recorrente e central da clínica das neuroses. Esse elemento sexual que se manifesta na franja da tênue conjunção entre as resistências e os fatores propiciadores da cura possui realmente um efeito explosivo, ainda mais se for levado em consideração que a transferência toma como vetor/resultante a pessoa do analista, o qual não pode se furtar à sua manifestação, tampouco responder a ela a partir de sua posição na fantasia.
Um recenseamento do percurso de Freud até esse momento autoriza a afirmação de que ele tem à disposição todos os elementos que compõe o conceito de transferência, excetuando a sua função de motor do tratamento. Esse componente recebe destaque no posfácio, onde é apresentado uma primeira teorização unificada da transferência. Serão comentadas de forma pormenorizada as pouco mais de três páginas onde uma organização inicial do conceito sob o ângulo da técnica é apresentada. Este, portanto, é considerado o segundo momento da abordagem da transferência do livro.

Primeiramente, Freud destaca que foi necessário a dissolução dos vínculos transferenciais para que parte dos sintomas de Dora desaparecessem. Salienta que essa melhora não deve ser tomada como um fato fortuito e aleatório. Para ele, a remissão dos sintomas é efeito retroativo do trabalho psíquico operado durante o tratamento. Ocorre aqui a retomada da tese de que o analista participa dos sintomas do analisado, no entanto, desta vez, ela está articulada à explicação da operacionalidade da análise. A transferência não é mais avaliada como um resíduo do sintoma que resiste ao tratamento. Ao invés disso, ela própria torna-se a principal força motriz do tratamento.

Freud insiste na participação de fortes componentes sexuais na composição do laço transferencial, que define como "novas edições (Neuauflagen), reproduções (Nachbildung) de tendências (Regungen) e fantasias (Phantasien), que com o avançar da análise devem ser despertadas e tornadas conscientes" (Freud, 1905/1997c, p. 180). Via de regra, esse processo ocorre pela "substituição" (Ersetzung) de uma pessoa anterior (da vida da paciente) pelo médico (p. 180). Destaca o caráter de realidade e atualidade desse investimento transferencial: "uma sequência inteira de acontecimentos (Erlebnisse) psíquicos anteriores são revividos (wieder lebendig), não como (fatos) passados, mas como um relacionamento atual com o médico" (p. 180).

Freud conclui, afirmando que a transferência deve ser tomada como um fenômeno cotidiano e espontâneo. Logo, a situação analítica não cria a transferência; apenas faz uso dela para produzir seus efeitos de cura. Assim, como no episódio da flauta de Hamlet, Freud defende que o manejo da transferência é o elemento mais difícil e delicado da técnica analítica, superando em grau de dificuldade à técnica da interpretação. Acrescenta que transferência é ao mesmo tempo o maior "impedimento" (Hinderniss) e o mais poderoso "instrumento de intervenção" 
(Hilfsmittel) (p. 182). Isso porque, em função das resistências, o analisando "atua" (agierte) (p. 182) na transferência com o analista um pedaço de suas lembranças e fantasias, em vez de reproduzi-las pela fala, o que frequentemente torna as manifestações da transferência um acontecimento opaco e incompreensível, se tomadas isoladamente.

A cronologia da redação do caso Dora esboçada acima também fornece elementos para explorar a sincronia entre o rompimento com Fliess e a retomada do tema da transferência na obra de Freud. É lícito supor que um processo análogo à transformação dos sintomas de Dora em função da dissolução do vínculo transferencial estabelecido durante o tratamento pode ter acontecido com o próprio Freud. Em função disso, a conceituação da transferência pode ter sido alavancada pela dissolução do laço transferencial com Fliess. Dessa forma, é possível afirmar que Freud explora não só as manifestações clínicas de seus pacientes, mas também as suas próprias, no percurso de teorização do fenômeno da transferência.

Sobre isso, são elucidativas às contribuições de Porge (1998) e Vidal (2010). A troca de cartas entre Freud e Fliess - até então o seu confidente mais próximo - encerra-se em 1904, aproximadamente na mesma época da escrita do posfácio do caso Dora. Na verdade, a interrupção da comunicação entre ambos, assim como acontece com Dora, é escandida em dois momentos distintos, cada um deles envolvendo uma estratégia específica de desinvestimento e realocação das energias psíquicas. Tal fato, no entanto, não diminui o impacto que exerceu na obra de Freud o rompimento definitivo, marcado por acusações de plágio proferidas por Fliess.

Porge (1998) destaca que um primeiro movimento de desinvestimento ocorre quando Freud publica A Interpretação dos Sonhos. Fliess é destituído do lugar de interlocutor privilegiado que ocupara até então. Freud a partir daí passa a se dirigir à comunidade de analistas, que ele supõe como ponto de endereçamento de seus escritos. De fato, as correspondências - pelo menos as que são de domínio público - diminuem bruscamente a partir do final de 1902, sendo retomadas somente em 1904 em função de uma polêmica na qual Fliess acusa Freud de ser conivente ou mesmo cúmplice de um suposto roubo de ideias, que envolveria a teoria da bissexualidade.

As últimas cartas atestam uma mudança drástica no tom afetivo se comparado a outras épocas. Freud defende-se, expõe sua versão dos fatos, apre- senta indícios de que a concepção de bissexualidade cuja autoria Fliess reivindica pode ser encontrada em outras fontes e envia uma cópia dos Três Ensaios Sobre a Sexualidade em processo de conclusão. Desta feita, o envio do manuscrito possui um objetivo diferente. Freud não espera o aval do de Fliess, apenas pede que $o$ antigo amigo censure as passagens que ele acredita derivadas do plágio do qual se queixa. Freud, por sua vez, dispõe-se a acatar incondicionalmente as recomendações de Fliess de modo a não dar margens para o acirramento do conflito. Essa derradeira carta de Freud presente na coletânea de Masson (1986) está datada de 27 de julho de 1904. O caso Dora é publicado em outubro de 1905.

\section{Conclusão}

O conceito de transferência resulta de um processo longo e tortuoso, que envolve tanto a descrição de fenômenos da clínica como a gradual construção de um referencial metapsicológico. A convergência dessas duas linhas de trabalho permitiu que alguns impasses e acontecimentos fossem interrogados a partir de uma nova perspectiva. Dessa forma, a construção do caso Dora e o rompimento com Fliess exerceram a função de catalisador no processo de resgate e elaboração do acumulado clínico, propiciando a formulação do conceito de transferência no âmbito da técnica.

É possível depreender dessa discussão que o analista desde o princípio está implicado no fenômeno da transferência, o que exige dele a tomada de uma posição ética, no sentido de que não há um agir predeterminado por uma orientação que lhe sirva de norma. A técnica constitui uma baliza que pode orientar as decisões do analista, mas tal baliza está longe de funcionar como um protocolo fechado que exclui a dimensão desejante do sujeito que opera com ela. Tal perspectiva possui implicações metodológicas e políticas fortes, haja vista que não há uma isenção integral possível do sujeito na clínica. Ainda que Freud se esmere por alcançar um certo grau de neutralidade, essa meta não pode ser entendida como análoga ao que hoje permeia a pesquisa nas ciências naturais.

Quando Freud destaca o caráter irremediavelmente sexual da transferência, sua irrupção como uma questão vivida no presente de cada sujeito e seu modo fragmentário e opaco de se manifestar, ele também nos lança o desafio de criar as condições para que uma nova análise possa acontecer. Cada situação, 
portanto, exige arranjos singulares para a produção do laço social analítico. A transferência promove um deslocamento da discussão sobre as condições para realização de uma análise do âmbito da reprodução de padrões (standards ou settings) para a instauração de um modo diferenciado de discursividade. Assim, pela via da transferência, ele é levado a interrogar as possibilidades de aplicação da psicanálise em diferentes contextos, situando seus limites e potencialidades no caso a caso. Decorre daí a necessidade de se criar um modo específico de investigar e transmitir com rigor os produtos da pesquisa em psicanálise, sem se furtar ao debate científico, mas também sem descaracterizar a especificidade metodológica do fazer analítico para se adaptar a um modelo de ciência que não inclui o inconsciente como categoria de trabalho.

Até onde um psicanalista pode ir sem desvirtuar sua práxis e abrir mão de seus fundamentos éticos? Essa talvez seja a pergunta que torna atual o legado freudiano sobre a transferência. O manejo da transferência continua sendo um tema delicado e central da clínica que demanda do psicanalista um constante exercício de inventividade técnica e teórica aliada a um rigor ético e metodológico.

\section{Referências}

André, J. (2013). O a posteriori transferencial dos traumas do início da vida. Ágora (Rio J), 16(spe), 127-140. https:// doi.org/10.1590/S1516-14982013000300009

Ayouch, T. (2015). Clínica psicanalítica da língua: vias associativas interlinguísticas, tradução e transferência. Estudos de Psicologia (Campinas), 32(1), 97-107. https://doi.org/10.1590/0103-166X2015000100009

Baratto, G. (2010). Genealogia do conceito de transferência na obra de Freud. Estilos da Clínica, 15(1), 228-247. Recuperado de http://pepsic.bvsalud.org/scielo.php?script=sci_arttext\&pid=S1415-71282010000100015

Breuer, J., Freud, S. (1999). Studien über Hysterie. Frankfurt am Main: Fischer Taschenbuch. (Originalmente publicado em 1895).Bursztyn, D. C., Figueiredo, A. C. (2012). O tratamento do sintoma e a construção do caso na prática coletiva em saúde mental. Tempo Psicanalítico, 44(1), p. 131-145. Recuperado de http://pepsic.bvsalud.org/ scielo.php?script=sci_arttext\&pid=S0101-48382012000100008

Castilho, A.L.P. (2013). Revisitando o primeiro modelo freudiano do trauma: sua composição, crise ehorizonte de persistência na teoria psicanalítica. Ágora (Rio J), 16(2), 235-250. https:// doi.org/10.1590/S1516-14982013000200004

Costa e Silva, C. A. A. B. (2014). Das relações iniciais entre interpretação e transferência no desenvolvimento do método freudiano. Psicologia: Ciência e Profissão, 34(3), 704-714. https://doi.org/10.1590/1982-3703001452013

Dunker, C. I. L. A psicose na criança: tempo, linguagem e sujeito. São Paulo, SP: Zagodoni, 2013.

Freud, S. (1962). Aus den Anfängen der Psychoanalyse: Briefe an Wilhelm Fliess (Abhandlungen und Notizen aus den Jahren 1887-1902). Frankfurt am Main: Fischer.

Freud, S. (1997). Bemerkungen über die Übertragungsliebe (Weitere Rätschlage zur Tecknik der Psychoanlyse III). In: Studienausgabe: (v. Ergänzungsband, p. 217-230). Frankfurt am Main: S. Fischer. (Originalmente Publicado em 1915)

Freud, S. (1997a). Bruckstück einer Hysterie-Analyse. In Studienausgabe (v. VI, p. 83-186). Frankfurt am Main: Fischer Taschenbuch Verlag. (Originalmente publicado em 1905)

Freud, S. (1997c). DerWitz und seine Beziehung zum Unbewuusten. In Studienausgabe: (v. IV, pp. 9-219). Frankfurt am Main: S. Fischer. (Originalmente Publicado em 1905)

Freud,. (1997). Die freudsche psychonalytische Methode. In Studienausgabe (v. Ergänzungsband, pp. 99-106). Frankfurt a. M.: S. Fischer. (Originalmente publicado em 1904).

Freud, S. (1997). Die Sexualität in der Ätiologie der Neurose. In: Studienausgabe (v. V, pp. 11-35). Frankfurt am Main: Fischer Taschenbuch. (Originalmente publicado em 1898).

Freud, S. (1997). Die Traumdeutung. Frankfurt am Main: Fischer Taschenbuch. (Originalmente publicado em 1900).

Freud, S. (1997). Konstruktionen in der Analyse. In: Studienausgabe: (v. Ergänzungsband, p. 393-406). Frankfurt am Main: S. Fischer. (Originalmente Publicado em 1937) 
Freud, S. (1999). Über Deckerinnerungen. In $G W$ (v. I, pp. 529-555). Frankfurt am Main: Fischer. (Originalmente publicado em 1899).

Freud, S. (1997b). Über Psychotherapie. In Studienausgabe, (v. Ergänzungsband, p. 107-119). Frankfurt a. M.: S. Fischer. (Originalmente publicado em 1905).

Freud, S. (1997). Wege der psychoanalytischen Therapie. In: Studienausgabe: (v. Ergänzungsband, p. 239-249). Frankfurt am Main: S. Fischer. (Originalmente Publicado em 1919)

Freud, S. (1999). Zum Psychischen Mechanismus der Vergesslichkeit. In $G W$ (v. I, pp. 517-527). Frankfurt am Main: Fischer. (Originalmente publicado em 1898).

Freud, S. (1997). Zur Ätiologie der Hysterie. In Studienausgabe (v. VI, pp. 51-81). Frankfurt am Main: Fischer Taschenbuch. (Originalmente publicado em 1896).

Freud, S. (1999). Zur Geschichite der Psychoanalytischen Bewegung. In: $G W$ (v. X, pp. 43-113). Frankfurt am Main: Fischer. (Originalmente publicado em 1914)

Freud, S. (1999). Zur Psychopathologie des Alltagslebens. In $G W$ (v. IV). Frankfurt am Main: Fischer. (Originalmente publicado em 1901).

Gay, P. (1989). Freud: uma vida para nosso tempo. São Paulo, SP: Companhia das Letras.

Honda, H. (2013). O estatuto conceitual do inconsciente em Freud e algumas de suas implicações para a prática psicanalítica. Ágora (Rio J), 16(spe), 41-57. https://doi.org/10.1590/S1516-14982013000300004

Laplanche, J., \& Pontalis, J.-B. (1998). Vocabulário de psicanálise. São Paulo, SP: Martins Fontes.

Masson, J. M. (1986). Correspondência completa de Sigmund Freud para Wilhelm Fliess (1887/1904). Rio de Janeiro, RJ: Imago.

Maurano, D. (2006). A transferência: uma viagem rumo ao continente negro. Rio de Janeiro, RJ: Jorge Zahar.

Maurano, D. (2010). Histeria: o princípio de tudo. Rio de Janeiro, RJ: Civilização Brasileira.

Mezan, R. (2014). O tronco e os ramos. São Paulo, SP: Companhia das Letras.

Miller, J.-A. (1987). Percurso de Lacan: uma introdução. Rio de Janeiro, RJ: Zahar.

Porge, E. (1998). Freud/Fliess: mito e quimera da autoanálise. Rio de Janeiro, RJ: Jorge Zahar.

Porge, E. (2003). Além da neurose de transferência. Revista Literal, 6, 127-166.

Porge, E. (2013). O inapanhável objeto do savoir-faire na análise. Estudos de Psicanálise, (40), 49-61. Recuperado de http://pepsic.bvsalud.org/scielo.php?script=sci_arttext\&pid=S0100-34372013000200006

Rabêlo, F. C., \& Dias, R. R. (2013). A transferência: dos primórdios da psicanálise aos estudos sobre histeria. Estilos da Clínica, 18(3), p.574-590. Recuperado de http://pepsic.bvsalud.org/scielo.php?script=sci_arttext\&pi$\mathrm{d}=\mathrm{S} 1415-71282013000300010$

Vidal, P. E. V. (2010). A invenção da psicanálise e a correspondência Freud/Fliess. Estilos da Clínica, 15(1), 14-25. Recuperado de http://pepsic.bvsalud.org/scielo.php?script=sci_arttext\&pid=S1415-71282010000200012

\section{Fabiano Chagas Rabêlo}

Mestre pela Universidade Federal do Ceará, Fortaleza - CE. Brasil.

E-mail: fabrabelo@hotmail.com

Leonardo Danziato

Doutor pela Universidade Federal do Ceará, Fortaleza - CE. Brasil. Docente da Universidade de Fortaleza - CE. Brasil. E-mail: leonardodanziato@unifor.br

Carlos José Cerqueira Veras Filho

Acadêmico de Psicologia pela Universidade Federal do Piauí, Teresina - PI. Brasil.

E-mail: casefilho@yahoo.com.br 
Rodrigo Barbosa Silva Quadros

Mestrando pela Universidade Federal do Ceará, Fortaleza - CE. Brasil.

E-mail: rodrigo8silva@hotmail.com

\section{Gustavo Oliveira Carvalho}

Acadêmico de Psicologia pela Universidade Federal do Piauí, Teresina - PI. Brasil.

E-mail: gustavooliveira100@gmail.com

Endereço para envio de correspondência:

Rua Alfeu Aboim, 511, apt. 1401. Cep: 60.175-375.

Fortaleza-CE. Brasil.

Recebido 23/10/2015

Aprovado 14/12/2016

Received 10/23/2015

Approved 12/14/2016

Recibido 23/10/2015

Aceptado 14/12/2016

Como citar: Rabêlo, F. C., Danziato, L., Veras Rilho, C. J. C., Quadros, R. B. S., \& Carvalho, G. O. (2017).

Os fundamentos da técnica da transferência de 1895 a 1905. Psicologia: Ciência e Profissão, 37(1): 132-145.

https://doi.org/10.1590/1982-3703003712015

How to cite: Rabêlo, F. C., Danziato, L., Veras Rilho, C. J. C., Quadros, R. B. S., \& Carvalho, G. O. (2017). The fundamentals of the transference's technique from 1895 until 1905. Psicologia: Ciência e Profissão, 37(1): 132-145. https://doi.org/10.1590/1982-3703003712015

Cómo citar: Rabêlo, F. C., Danziato, L., Veras Rilho, C. J. C., Quadros, R. B. S., \& Carvalho, G. O. (2017). Los fundamentos de la técnica de transferencia de 1895 hasta 1905. Psicologia: Ciência e Profissão, 37(1): 132-145. https://doi.org/10.1590/1982-3703003712015 